\title{
eDtrorial RBEP
}

http://dx.doi.org/10.1590/S2176-6681/258227581

Caros leitores e leitoras,

O número 245 da Revista Brasileira de Estudos Pedagógicos (RBEP) apresenta instigantes contribuições ao campo da educação no Brasil. Além dos dez artigos que o compõem, de um relato de experiência e de uma resenha, trazemos também, em destaque, uma entrevista com Anne-Marie Chartier. A professora e pesquisadora francesa tem se tornado, nas últimas décadas, uma importante referência nos debates educacionais ocorridos no País, não apenas no que se refere à pesquisa acadêmica - realizada principalmente na área da história do ensino da leitura e da escrita -, mas também no que diz respeito à formulação de políticas públicas e à formação de professores. Na entrevista, realizada por Carla Ferreira, Eliane Marta Teixeira Lopes e Mônica Rahme, em outubro de 2015, em Mariana (MG), onde esteve como professora visitante na Universidade Federal de Ouro Preto (Ufop), Anne-Marie aborda temas diversos, como os limites e as potencialidades da pesquisa realizada nas universidades, a história comparada, o "retorno ao religioso", observado contemporaneamente na educação, a educação inclusiva e a história da educação musical. Traz, ainda, reflexões sobre o potencial da obra do teórico francês Michel de Certeau para se repensar a educação e a cultura.

Os artigos publicados no número abordam, majoritariamente, a formação - inicial e continuada - e a profissão docentes, evidenciando 
a preocupação dos pesquisadores brasileiros em compreender, de modo mais aprofundado, o(a) professor(a) e seus saberes. A formação inicial dos docentes é discutida por meio de estudos realizados em/sobre cursos de licenciatura, principalmente de Pedagogia. Em "'Quero ser professora': a construção de sentidos da docência por meio do Pibid", Giana Yamin, Míria Campos e Bartolina Catanante analisam os sentidos da docência (re) construídos por acadêmicas de licenciatura em Pedagogia durante o percurso como bolsistas do Programa Institucional de Bolsas de Iniciação à Docência (Pibid), da Universidade Estadual de Mato Grosso do Sul (UEMS), buscando avaliar o impacto do programa na formação profissional. Problematizando outro aspecto da formação docente e utilizando metodologia distinta, o artigo "A abordagem da avaliação educacional em larga escala nos cursos de graduação em Pedagogia", de Marcela Silva, Carolina Reihn, Andressa Soares e Tufi Soares, resulta de um levantamento da presença e da percepção da relevância da abordagem referida no título do artigo, nos cursos de Pedagogia presenciais, públicos e privados, no País. O último artigo reunido neste grupo - "Letramento acadêmico em um curso de Geografia: uma perspectiva etnográfica" -, de autoria de Maria do Socorro Macedo e Bernardino Neves-Júnior, aborda, por sua vez, uma experiência em um curso de licenciatura em Geografia, buscando compreender as práticas de letramento acadêmico nele observadas.

Em relação à formação continuada, Dalva Godoy e Fernanda Viana, em "Conteúdos linguísticos como subsídio à formação de professores alfabetizadores - a experiência do Brasil e de Portugal", objetivam identificar, em dois programas de formação de professores alfabetizadores - no Brasil, o Pacto Nacional pela Alfabetização na Idade Certa (Pnaic) e, em Portugal, o Programa Nacional do Ensino do Português (Pnep) -, os conteúdos linguísticos relacionados ao ensino da leitura que os fundamentam, com vistas a compreender como as descobertas científicas penetram o campo pedagógico. Em "Formação docente continuada, desenvolvimento de práticas pedagógicas em sala de aula e promoção da saúde do professor: relações necessárias", Anselmo Lima e Dalvane Althaus, baseados em uma abordagem teórico-metodológica de "caráter clínico, desenvolvimental e dialógico-argumentativo", analisam os resultados de uma ação de formação docente continuada em uma universidade pública brasileira, buscando discutir as relações entre a referida ação, o desenvolvimento de práticas pedagógicas em sala de aula e a promoção da saúde dos professores. Por fim, ainda no que se refere à formação continuada, em "Dilemas da docência na educação a distância: um estudo sobre o desenvolvimento profissional na perspectiva dos tutores da Rede e-Tec Brasil", Luciane Penteado Chaquime e Daniel Mill discutem os resultados de um estudo que analisou como a atuação na tutoria virtual de cursos de educação a distância (EaD), mediados por tecnologias digitais de informação e comunicação e ofertados 
por um instituto federal de educação de São Paulo, pode contribuir para o desenvolvimento profissional docente.

A preocupação com a atuação docente revela-se, sobretudo, no artigo "Concepção de professores do ensino fundamental sobre a dislexia do desenvolvimento", em que as autoras (Maria de Lourdes Tabaquim e colaboradoras), partindo do pressuposto de que o não conhecimento do transtorno inviabiliza o adequado enfrentamento das dificuldades na aprendizagem, buscaram caracterizar o nível de informação - sobre a dislexia - de professores de língua portuguesa das séries finais do ensino fundamental, das redes estadual e particular.

Três artigos, que abordam temas diversos, foram ainda publicados nesta edição da $R B E P$, entre os quais dois se baseiam em pesquisa documental: Gladir Cabral, Celdon Fritzen e Carlos Carola, em "O positivismo e a literatura infantil: desmistificando a doxa e mitificando a ciência", analisam o trabalho da Comissão Nacional de Literatura Infantil (CNLI), instituída pelo Ministério de Gustavo Capanema em 1936, no governo do então presidente Getúlio Vargas, a fim de oferecer subsídios para adoção de medidas e criação de projetos que favorecessem a formação de leitores nas escolas brasileiras da época. Em "A heteroglossia e o projeto políticopedagógico", Iverton Gessé Ribeiro Gonçalves analisa, sob a perspectiva dialógica, as vozes sociais que cruzam o projeto político-pedagógico de uma escola. Por fim, publicamos o trabalho "'O que você quer ser quando crescer? '. Escolarização e gênero entre crianças de camadas populares urbanas", de autoria de Adriano Senkevics e Marília Carvalho, que objetivou compreender como o sucesso escolar das meninas pode estar relacionado às diferenças de gênero observadas nas perspectivas de futuro de meninas e de meninos de uma escola de ensino fundamental da rede municipal de São Paulo.

Buscando incentivar a disseminação de ações pedagógicas que, fundamentadas teoricamente e analisadas criticamente, possam instigar nossos leitores a visualizarem outras possibilidades em seus fazeres profissional e acadêmico, a RBEP tem buscado, sempre que possível, publicar relatos de experiência. Neste número, no trabalho "Saber acadêmico versus saber popular: a literatura de cordel no ensino de práticas agrícolas", Patrícia Carneiro Souto apresenta resultados de uma experiência de produção de literatura de cordel em uma universidade localizada na região do semiárido da Paraíba, com o objetivo de discutir os problemas e danos que o fogo indiscriminado pode causar, mostrando algumas técnicas fundamentais e recomendações básicas para a realização da queima controlada.

Recentemente, a RBEP ampliou, para os seus colaboradores, a possibilidade de resenharem não apenas livros, mas também filmes, considerando o potencial formativo (inclusive estético - e não apenas referente à temática tratada) que essas obras possuem tanto para 
pesquisadores quanto para professores e estudantes. Essa decisão é ainda mais relevante quando consideramos que, a partir de 2014 (Lei ${ }^{\circ}$ 13.006/2014), se tornou obrigatória a exibição de filmes brasileiros nas escolas. Nessa direção, publicamos, neste número, a primeira resenha sobre um filme. Nela, intitulada "Para além dos olhos", Eugênio Oliveira e Geovana Martins analisam $O$ som ao redor, do premiado diretor pernambucano Kleber Mendonça Filho, destacando aspectos da narrativa, das locações e da trama das principais personagens da história.

Diante dessa diversidade de possibilidades de leitura, esperamos que o(a) leitor(a) se sinta convidado(a) e instigado(a) a ampliar os modos de olhar o fenômeno da educação, sempre com profundidade e rigor analíticos.

\section{Editoria Científica}

Ana Maria de Oliveira Galvão Ana Maria Iório Dias Flávia Obino Corrêa Werle

Guilherme Veiga Rios

Maria Clara Di Pierro

Rogério Diniz Junqueira

Wivian Weller 